University of Nebraska - Lincoln

DigitalCommons@University of Nebraska - Lincoln

$11-1-2004$

\title{
Development of auditory event-related potentials in young children and relations to word-level reading abilities at age 8 years
}

\author{
Kimberly Espy \\ University of Nebraska-Lincoln, kespy2@unl.edu \\ Dennis L. Molfese \\ University of Louisville,dmolfese2@unl.edu \\ Victoria J. Molfese \\ University of Louisville, vmolfese2@unl.edu \\ Arlene Modglin \\ Southern Illinois University
}

Follow this and additional works at: https://digitalcommons.unl.edu/dcnlfacpub

Part of the Neurosciences Commons

Espy, Kimberly; Molfese, Dennis L.; Molfese, Victoria J.; and Modglin, Arlene, "Development of auditory event-related potentials in young children and relations to word-level reading abilities at age 8 years" (2004). Developmental Cognitive Neuroscience Laboratory - Faculty and Staff Publications. 6.

https://digitalcommons.unl.edu/dcnlfacpub/6

This Article is brought to you for free and open access by the Developmental Cognitive Neuroscience Laboratory at DigitalCommons@University of Nebraska - Lincoln. It has been accepted for inclusion in Developmental Cognitive Neuroscience Laboratory - Faculty and Staff Publications by an authorized administrator of DigitalCommons@University of Nebraska - Lincoln. 
Published in Annals of Dyslexia 54:1 (2004), pp. 9-38. Copyright ( 2004 by The International Dyslexia Association; published by Springer Verlag. Used by permission. http://www.springer.com/linguistics/languages+\&+literature/journal/11881

Submitted June 1, 2003; accepted November 10, 2003.

\title{
Development of Auditory Event-Related Potentials in Young Children and Relations to Word-Level Reading Abilities at Age 8 Years
}

\author{
Kimberly Andrews Espy, Southern Illinois University School of Medicine
}

Dennis L. Molfese \& Victoria I. Molfese, University of Louisville Arlene Modglin, Southern Illinois University

Corresponding author - K. A. Espy

\begin{abstract}
A relationship between brain responses at birth and later emerging language and reading skills have been shown, but questions remain whether changes in brain responses after birth continue to predict the mastery of language-related skills such as reading development. To determine whether developmental changes in the brain-based perceptual skills are systematically related to differences in wordlevel reading proficiency at age 8 years, brain event-related potentials (ERPs) to speech and nonspeech stimuli were recorded annually at the ages of 1 through 8 years in a sample of 109 typically developing children. Two measures of wordlevel reading (one that requires decoding of real words and one of pseudowords) were administered at age 8 years. Growth curve analysis, using the hierarchical linear models, related reading performance (average versus low) to the longitudinal maturation in the ERP waveform peak and latencies. Maturational changes (e.g., slope, acceleration, and cubic growth) in N1 amplitude from ages 1 to 4 were related to proficiency in decoding pseudoword stimuli only, with children who were less proficient in decoding pseudowords evidencing more steeply negative declines in amplitude with age, particularly at the frontal and parietal recording sites in response to both speech and nonspeech stimuli. In contrast, proficiency in decoding real words was related to developmental changes in N2 amplitudes from ages 4 to 8 only at the parietal recording site, and only in response to nonspeech stimuli. The early development of biologically based differences in the perception and processing of auditory information contributes to later group differences in reading proficiencies at school age.
\end{abstract}


It now widely recognized that phonological processes provide an important basis for the development of reading skills. Phonological processing refers to the ability to discriminate phonetic contrasts, and includes discrimination of speech sounds and categorical perception (voice-onset-time, place of articulation) as well as the ability to segment and manipulate phonemes and larger units. Phonological skills important for analyzing the sound patterns in spoken words are present at or near birth and others develop in early infancy. For example, young infants can discriminate between speech sounds of their native language environment and those of other languages (Eilers, 1977; Eilers, Wilson, \& Moore, 1977; Eimas, Siqueland, Jusczyk, \& Vigorito, 1971; Molfese \& Molfese, 1979a, 1979b, 1980, 1985). This sensitivity changes in later infancy toward an increasing sensitivity to contrasts unique to the infant's language environment, a change that appears to facilitate language acquisition. Use of these phonological contrasts provides one foundation for the rapid rise in the proficiency of language expression that is initiated at the beginning of the first year where the child learns to match expressive sounds to phonological templates (e.g., Huttenlocher, Haight, Bryk, Seltzer, \& Lyons, 19911). With further development, preschool children can segment spoken monosyllable words into onsets and rimes, and thus play nursery rhyme games (Vellutino \& Scanlon, 1987). As they continue to develop, children learn to segment polysyllabic words into syllables as they approach kindergarten age and monosyllabic words into phonemes around first grade (Denton \& West, 2002; Liberman, Cooper, Shankweiler, \& Studdert-Kennedy, 1967). Over the past decade, a consensus of findings has emerged among researchers that phonological processing skills are fundamental to 
language development and to subsequent reading abilities (Brady, 1991; Fletcher, Foorman, Shaywitz, \& Shaywitz, 1999; Wagner, Torgesen, \& Rashotte, 1994).

Although behavioral studies support the validity of phonological processing among other cognitive skills as important skills in the development of reading, what remains unclear are the precise mechanisms that underlie the proficient use of phonological processing skills in reading. Molfese and Molfese (Molfese, Molfese, Key, Modglin, Kelley, \& Terrell, 2002; Molfese \& Molfese, 2002) have postulated that reading and other language proficiencies have a foundation in neurally based speech perception abilities. These basic abilities are present from birth to a degree, and provide the basis for subsequent language development including phonological and phonemic processing. Specifically, at birth, infant perceptual abilities discriminate among sound-based variation in the environment (Molfese \& Molfese, 1979b). For most infants, basic perceptual abilities are similar, readily enabling discrimination of speech elements within the environment in effective ways. However, for some infants, variations in how their brains quickly and efficiently detect and process environmental speech-related information, as evidenced by differences in auditory event-related potentials (ERPs), may disadvantage them in the acquisition of more complex language-related abilities during subsequent development. For these children, such perceptual differences may ultimately lead to language delays and/or faulty or slower processing of speech-related information (Kraus et al., 1996; Merzenich et al., 1996; Molfese and Molfese, 1985, 1997; Tallal et al., 1996), and subsequently impact the development of reading skills.

In this regard, Molfese and Molfese have demonstrated, with a longitudinal sample of children, that newborn infants can discriminate phonological contrasts such as place of articulation (e.g., Molfese \& Molfese, 1979b, 1985), evidenced by different ERP waveform characteristics reflected in both left hemisphere and bilateral hemisphere responses to specific consonant sounds. By the age of 2 months, infants discriminate between voicing contrasts (Molfese \& Molfese, 1979a). There are continued age differences in these abilities that stabilize between age 3 and 4 years (Molfese \& Molfese, 1988). Further, Molfese and Molfese (1985) found that certain components of the ERP collected within 2 days of birth to specific consonant sounds and their nonspeech analogues predicted language performance at age 3 years. Group differences (high versus low 
language scores) were reflected in a large initial negative peak, N1 (peak latency $=220 \mathrm{~ms}$ ). A second negative peak, N2 (peak latency $=$ $630 \mathrm{~ms}$ ), also discriminated between these two groups of children although it accounted for less variance. These same ERP regions also discriminated between different Stanford-Binet verbal scores at 5 years of age (Molfese \& Molfese, 1997).

Finally, differences in neonatal ERP waveforms were related to reading scores on the WRAT-R at age 8 years in normally developing children and children with reading disabilities (Molfese, 2000; Molfese, Molfese, \& Modglin, 2001). The N1 peak latency at the right temporal recording site and N1 peak latency at the left frontal site for the speech syllable /gi/ were related to the WRAT-R reading subtest score. In hierarchical discriminant function models, newborn ERP components accounted for nearly $10 \%$ of the variance in WRAT-R Reading subtest scores at age 8 years, and successfully discriminated between poor and normal reading groups. The same right temporal N1 latency to /gi/ was previously identified at 5 years as predictive of the Stanford-Binet verbal scores at age 5 (Molfese \& Molfese, 1997).

These findings demonstrated potent relations between newborn ERP waveforms, particularly that of the latency of the early negative going wave N1, and later language and reading proficiencies. However, few studies have investigated the developmental trajectory of ERPs longitudinally. There is evidence of maturation of the ERP waveform throughout childhood (Espy, Molfese, Simos, \& Modglin, 2003), with dramatic changes in ERP peak amplitudes and peak latencies, particularly in the preschool period. Therefore, individual differences in the developmental trajectories of ERP waveforms after birth also might relate systematically to reading skills later in development. Recent advances in the analysis of longitudinal data now permit better specification of the actual form of the developmental trajectory, particularly in the case where the dependent variable truly is on a ratio scale, as is the case with both ERP amplitude $(\mu \mathrm{V})$ and latency (msec). The techniques, known as growth curve analysis or hierarchical linear modeling (Willett, 1988; Raudenbush \& Bryk, 2002), take advantage of the nested nature of repeated measurements within a subject to yield information simultaneously about individual differences in growth parameters and systematic group differences. For example, such techniques have been utilized successfully to understand outcome following traumatic brain injury in children (e.g., Yeates et al., 1997; Francis, Fletcher, Steubing, Davidson, \& Thompson, 1991), de- 
velopmental growth in reading skills (e.g., Francis, Shaywitz, Steubing, Shaywitz, \& Fletcher, 1996), and neurobehavioral development in neonates exposed to cocaine prenatally (Espy, Francis, \& Riese, 2000; Espy, Riese, \& Francis, 1997). This approach is particularly useful in the context of an extended longitudinal study as subjects with some missing data can be included, thereby maximizing the number of children who can be studied and expanding the resulting generalizability of the findings.

Evidence from developmental trajectories of ERP waveforms show that individual differences in the development of brain-based perceptual skills may be related to subsequent verbal proficiencies. In typically developing children, Molfese, Molfese, and Espy (1999) found that reductions in ERP latency of the early, negative waveforms were of smaller magnitude in 8-year-old children who scored $\leq 95$ on the WISC-III Verbal Comprehension Index $(M=-7.7 \mathrm{msec} /$ year $)$ than in those children who scored $>95(M=-12.6 \mathrm{msec} /$ year $)$. Developmental changes in the later, positive and negative waveform latencies were unrelated to verbal skills at this age. However, peak amplitudes were not investigated, and differential brain ERP responses between recording sites and stimulus conditions also were not examined to determine whether it was specific speech processing or more nonspecific linguistic discriminations that differentiated verbal skill proficiency.

Such findings provide an impetus to investigate broader developmental changes in brain-based perceptual skills and to determine the extent to which developmental trajectories of ERPs are related to individual differences in language-related proficiencies such as reading. Reported here are the results of two different approaches to the assessment of reading skills: WRAT-R Reading subtest (Jastak \& Wilkinson, 1984) and the Word Attack subtest from the WoodcockJohnson Psycho-Educational Test Battery-Revised (WJ-R) (Woodcock \& Johnson, 1989). WRAT-R Reading scores are used frequently in studies of word-level reading skills, but may not be the best instrument to reveal specific relations between perceptual skills and the phonological processes that underlie reading. The WRAT-R Reading subtest involves the decoding of both regular single words (with simple correspondence between grapheme and phonemes) and irregular single words (that do not follow grapheme to phoneme rules). However, familiarity confounds processing demands on the WRAT$\mathrm{R}$ Reading subtest as children may use sight-based or whole-word recognition strategies to decode words that are familiar, and rely on phonological strategies only on unfamiliar words (Share, 1995). Be- 
cause familiarity is determined in part by proficiency and, at a minimum, differs among individual children, relations between specific brain activity and WRAT-R Reading subtest performance may be attenuated. In contrast, the WJ-R Word Attack subtest was designed to specifically assess single word decoding by using nonsense pseudoword stimuli that vary systematically in phonetic difficulty. These nonsense pseudoword stimuli should be unfamiliar to all children, precluding children from relying on sight-based recognition strategies. Therefore, using both WRAT-R Reading and WJ-R Word Attack subtests enables comparison between how brain-based perceptual skills that discriminate between speech and nonspeech sounds thought to underlie reading abilities (as measured by ERPs) are related to performance on these different reading tasks. In this study, the developmental trajectory of ERP waveform peak amplitudes and latencies from ages 1 through 8 years were compared in poor and average readers, defined either by using WRAT-R Reading subtest scores or by the WJ-R Word Attack subtest scores. The development of ERP waveforms, specifically changes in the N1 peak amplitudes and latencies, were hypothesized to be related to reading proficiency at age 8 years, with a stronger relation for those ERPs recorded to speech stimuli compared to nonspeech stimuli. Furthermore, the development of ERP waveforms were posited to be related more consistently to reading proficiency assessed by the WJ-R Word Attack subtest than by the WRAT-R Reading subtest because of the more primary engagement of specific phonological processing skills necessary to subserve reading on the WJ-R Word Attack subtest.

\section{Methods}

\section{Participants}

ERPs were collected annually from a longitudinal sample of 109 children (48 males and 61 females), within two weeks of their birthday, at ages 1 through 8 years. These 109 children were selected for study inclusion from the total sample of children who participated in the study due to the availability of ERP data collected on at least three test occasions between the ages of 1 and 8 years, and for whom reading scores were available at age 8 years. ERP data collected at ages 1 through 8 years are included here to specifically test whether the development of perceptual skills beyond the newborn period were related to subsequent reading abilities, as relations to newborn recordings have been reported elsewhere (e.g., Molfese \& Molfese, 2000). 
All children were full-term at birth ( $\mathrm{M}$ birth gestational age $=39.42$ weeks; $\mathrm{SD}=1.95)$, with a mean birth weight of 3417.45 grams $(\mathrm{SD}=$ 654.31). Sociodemographically at age 4 years, mean maternal education was 14.4 years $(S D=1.0)$ with an approximate average annual family income of $\$ 33,000$, consistent with families of the surrounding region. Handedness measures also were obtained from the children using the 10-item short version of the Edinburgh Handedness Battery (Oldfield, 1971) at age 7 years, with scores ranging from +1.0 , indicating a strong right hand preference to -1.0 , indicating a strong left-hand preference. The mean laterality quotient for these 109 children was $+0.72(S D=0.46)$, indicating that the group as a whole was moderately right handed.

\section{Stimuli}

Four auditory stimuli that were a subset of the sounds employed by Cutting (1974), and subsequently by Molfese (Molfese \& Molfese, 1979a, 1985) were presented to each child. Two 3-formant speech stimuli were used / bi/ and /gi/ (with bandwidths of 60, 90, and $120 \mathrm{~Hz}$ for formants 1, 2, and 3, respectively), where differences in the initial second formant transition identified the different consonant sounds,/b/versus /g/. Two nonspeech sounds were composed of pure tones (i.e., having a bandwidth of $1 \mathrm{~Hz}$ ), where the formants were computed numerically to exactly match the central frequencies of the formants in the speech stimuli, including the initial transitions and peak intensity. Because the purpose of this study was to examine the relation between brain-based perceptual skills for speech versus nonspeech sounds and later reading abilities, differences in ERP waveforms in response to specific consonant contrasts such as the/bi/ and/gi/speech sounds were not analyzed, but rather were collapsed into a single speech stimuli condition, and the matched nonspeech sounds also were collapsed into a single nonspeech stimuli condition. Twenty-five repetitions of each of the four stimuli were presented in a blocked random order such that they were presented first in one random order of four sounds, and then by a different random ordering of these four sounds, and so on. Random time intervals that varied from 2.5 to $4.0 \mathrm{sec}$ were inserted between each stimulus.

Following human subject's approval, informed consent was obtained from the parent and assent from the child. Six silver cup electrodes were placed on the child's scalp using the 10-20 system (Jasper, 1958), with 1 electrodes placed over the left (T3) and right (T4) temporal areas, at the midpoint between the left or right external au- 
ditory meatus and Fz (FL and FR, respectively), and at the midpoint between the left or right external auditory meatus and $\mathrm{Pz}$ (PL and $\mathrm{PR}$, respectively). These electrodes were referred to electrodes placed on each earlobe and linked together (A1, A2). Artifacts related to eye movements were monitored by means of supraorbital and canthal electrodes placed in relation to the right eye. All pre-test and post-test scalp electrode impedances were $<5 \mathrm{kOhm}$, and impedances between scalp sites and the linked-ear references varied no more than $1 \mathrm{kOhm}$ in order to maintain the average of the two ear references as a true average reference. The average impedances obtained prior to testing did not exceed 1.5, and post-impedances taken immediately following the test session did not exceed 1.6.

\section{ERP Procedure}

Digitized values of the ERPs elicited from each child in response to the auditory stimuli were stored online during the recording session and subsequently analyzed by the EPACS ${ }^{\odot}$ software package (Molfese, 1988). All ERPs were digitized at $5 \mathrm{~ms}$ intervals for a period of $700 \mathrm{~ms}$ post stimulus onset, based on earlier work indicating that most of the stimulus relevant variability in the ERP signal elicited by these speech and nonspeech sounds ended at $700 \mathrm{~ms}$ following the onset of the stimulus (Molfese \& Molfese, 1979b, 1980, 1985). Artifact rejection, defined as peak voltage shifts greater than $+/-40$ $\mu \mathrm{V}$ for single trial responses, was conducted on ERPs obtained from all recording channels to remove ERP data contaminated by myogenic and ocular artifacts. Rejection rates were comparable across all children within each age group for each of the stimulus conditions, with mean artifact rejection rates ranging from $3 \%(S D=4.70)$ to $13 \%$ $(\mathrm{SD}=7.74)$. Following the artifact rejecting procedure, the single trial data were averaged separately for each of the six electrode sites and four stimulus conditions. In all, 48,456 averaged ERPs were obtained from the 109 children at each age from 1 through 8 years. Finally, ERP voltage values were baseline adjusted (separately for each averaged waveform) with respect to average voltage during the 75-ms prestimulus period prior to calculation of subsequent measures.

Baseline-to-peak analyses were carried out on all the averaged waveforms for the 109 children within each age group, where a separate grand average ERP first was created for each age group $(1,2,3$, $4,5,6,7$, and 8 years) by averaging together all of the ERPs obtained from the children at that age. These centroids served as visual guides 
for two researchers to independently identify the common peaks at each age across all children. Interrated reliability for peak identification was greater than .90 for all peak measures. Three peaks, which were readily identifiable in both the group average and in all the individual subject waveforms, were selected for analyses: the first reliable large negative peak deflection (N1) that varied from the prestimulus baseline after the onset of the stimulus, the large positive peak deflection (P2) that occurred immediately following this negativity, and the next negative peak (N2) that followed directly after the positivity. These peaks occurred at approximately $200 \mathrm{~ms}$ for N1, $350 \mathrm{~ms}$ for P2, and $475 \mathrm{~ms}$ for $\mathrm{N} 2$ across the 3- to 5-year-old groups. The average midpoint peak latencies for the 6- to 8-year-age groups were approximately $150 \mathrm{~ms}$ (N1), $300 \mathrm{~ms}$ (P2), and 450 (N2). Based on these latencies, the two negative most points and one most positive point were selected from each individual child's data previously averaged by condition and electrode site. The latencies for each of these peaks varied across electrode sites and between subjects. The maximum amount of variability allowed was $50 \mathrm{~ms}$ on either side of each peak predetermined in the centroid. Amplitude and latency values were recorded for each of these three peaks.

Reading Tests. At age 8 years, children were administered two reading tests during yearly testing sessions as part of the longitudinal study. The Word Attack subtest of the Woodcock-Johnson Psycho-Educational Battery-Revised (Woodcock \& Johnson, 1989) was administered to assess nonsense word decoding, unconfounded by familiarity. In the word attack subtest, children decode single nonsense words, some of which are irregular and some of which can be sounded out by regular phonetic rules. Normative data are available by age and grade level, where age level normative data was used to transform the raw score into the resultant standard score for grouping participants. The Wide Range Achievement Test-Revised (WRAT-R) (Jastak \& Wilkinson, 1984) Reading subtest also was administered to assess real word decoding abilities. This instrument provides a timeefficient index of single word reading. Children are presented with an array of 42 words and are instructed to read one word at a time. The number of words read correctly is scored. Normative data is available by age and grade level, where age level normative data was used to transform the raw score into a standard score for the purpose of parsing participants into groups.

As a group, the sample scored in the average range on both instruments with a mean WJ-R Word Attack score of $103.60(\mathrm{SD}=19.79)$ 
and mean WRAT-R Reading score of $98.22(\mathrm{SD}=14.49)$. The group was of average intellectual ability with a mean verbal composite IQ on the Wechsler Intelligence Scale for Children-III (Wechsler, 1991) of $108.51(\mathrm{SD}=11.71)$.

A categorical grouping scheme was used to facilitate ease of comparisons of growth trajectories between children of different reading abilities. Participants were divided into groups by their WJ-R Word Attack scores at age 8 years, where those with average scores (WAAVG group) were defined as those who obtained a standard score $\geq 90$, and children in the low scoring group (WA-LOW group) were defined as those who scored $\leq 89$. There were 96 children in the WAAVG group $(\mathrm{M}=106.48, \mathrm{SD}=11.80$; Range 90-137) and 13 in the WA-LOW group $(\mathrm{M}=82.31$; $\mathrm{SD}=7.17$; Range $62-89)$. The verbal composite IQ for the WA-AVG group was $109.76(\mathrm{SD}=9.60)$ and for the WA-LOW group was 97.45 (SD = 11.31). When the WRAT-R reading standard scores were used to create groups using the same cut-score, there were 79 children in the R-AVG group $(\mathrm{M}=104.79$, $\mathrm{SD}=9.92$, Range 91-126) and 30 in the WR-LOW group $(\mathrm{M}=80.67$, $\mathrm{SD}=8.67$; Range 61-89). Mean verbal composite IQs for the WRAVG and WR-LOW groups were $110.02(\mathrm{SD}=11.49)$ and 104.60 (SD $=11.56$ ), respectively.

In these 109 children, a total of 673 ERP recording sessions were conducted across the eight-year period. On average, children were assessed 6.2 times $(\mathrm{SD}=1.41)$ across the observation period from age 1 through 8 years $\left(\mathrm{M}_{\mathrm{age}}=490\right.$ years, $\left.\mathrm{SD}_{\mathrm{age}}=2.21\right)$, with the average age at the first evaluation of 1.78 years $(\mathrm{SD}=1.00)$ and at the last evaluation of 7.87 years $(S D=0.59)$. There were 8 children with three evaluations, 4 with four evaluations, 17 with five evaluations, 29 with six evaluations, 30 with seven evaluations, and 20 children who completed all eight ERP recording sessions. Correspondingly, there were 57 participants with ERP recordings at 1 year of age, 61 2-year-olds, 82 3-years-olds, 92 4-year-olds, 88 5-year-olds, 91 6-year-olds, 100 7-yearolds, and 102 8-year-olds. There were somewhat fewer 1 and 2 year assessments because it was more common for children this young to be less tolerant of the electrode placement procedures.

Not surprisingly, the number of ERP sessions completed, $F(1,128)$ $=31.69, p<.0001$, and the age at final session, $F(1,128)=107.98, p$ $<.0001$, differed between the study sample and the 21 children for whom WJ-R Word Attack and WRAT-R Reading scores were unavailable at age 8 years $\left(\mathrm{M}_{\text {number of evaluations }} 4.38 ; \mathrm{SD}_{\text {number of evaluations }}=1.28\right.$; $\mathrm{M}_{\text {age at final evaluation }}=5.86, \mathrm{SD}_{\text {age at final evaluation }}=1.53$ ). Dropout by age 8 
years was relatively uniform across the observation period, two children at age 3 years, two at age 4 , four at age 5 , five at age 6 , five at age 7 , and three at age 8 . The groups, however, were comparable in the age at first evaluation (missing group $\mathrm{M}=1.52, \mathrm{SD}=0.75 ; F[1,128]=$ $1.23, p>.26)$ and $\operatorname{sex}\left(12 \mathrm{M}, 9 \mathrm{~F}, \mathrm{X}^{2}[1, N=130]=.03, p>.86\right)$. Furthermore, there were no differences in the grand average ERP amplitudes $F(1,55078)=0.02, p>.89$ or latencies, $F(1,55078)=1.40, p>.23$ between the study sample and the 21 children with missing WJ-R word attack and WRAT-R reading scores. In terms of background characteristics, the 109 study participants and the 21 children for whom cognitive test data was unavailable did not differ in sex, $\chi^{2}(1, N=130)$ $=1.97, p>.16$, birth weight $F(1,128)=0.16, p>.69$; maternal education $F(1,126)=0.44, p>.51$ or family income $F(1,122)=0.01, p>.98$. Therefore, the missing data mechanism was treated as consistent with missing at random for the purposes of the subsequent analyses (Little \& Rubin, 1987; Schafer, 1997).

\section{Analysis}

Growth curve analysis using hierarchical linear modeling was utilized to analyze the longitudinal data, with a mixed model design and restricted maximum likelihood estimation, using SAS PROC MIXED, version 8.2. In order to estimate the individual model parameters, individual growth curves were calculated by regressing the pertinent ERP waveform peak amplitude and latency on child age at evaluation. Two sets of models were fit, unconditional models to determine the shape of the developmental trajectories of the ERP waveforms, and conditional models where the predictors of interest (reading group) were related to the growth parameters derived from the unconditional models. In these models, the intercept represents the ERP amplitude or latency at the centered age (age 4 years) where the linear slope parameter quantified the change in pertinent peak amplitude or latency per year of child age, also at the centered age. The quadratic term represented the extent to which the slope of the line tangent to the growth curve trajectory at 4 years of age increased (i.e., positive in sign) or decreased (i.e., negative in sign), where the cubic term described the extent to which this change in the slope of the line tangent was attenuated or amplified. To determine the specific form of individual growth in the unconditional models, plots of the individual and averaged growth trajectories were examined, mean growth parameter estimates and the variance in the parameter estimates were 
tested against a zero value, and competing covariance structures (unstructured versus autoregressive) were contrasted.

The unconditional models derived in Espy et al. (2003) were used here as they were thought to best represent the growth trajectories of ERP development across the age range studied. For the amplitude of the two negative peaks - N1 and N2-the growth rates in the early period (from ages 1 through 4 years), differed from those observed in the later period (ages 4 through 8 years). Therefore, for these peaks, the growth was specified using a piece-wise coding scheme (Raudenbush \& Bryk, 2002) that allowed for different growth trajectories and corresponding estimated parameters in each of these two periods. Growth was described best by a cubic function between ages 1 through 4 years, with a quadratic form between ages 4 through 8 years. Interestingly, the growth in P2 amplitude oscillated around a constant; therefore, an intercept-only model best described change in P2 amplitude. For ERP latencies, a cubic model best described change from ages 1 through 8 years for the N1 peak, whereas a quadratic model best fit for the P2 and N2 waveforms. There was evidence of different rates of growth in the peak latencies during the early period (ages 1 to 4 years) and the later (ages 4 through 8 years). All analyses were centered at age 4 years, the transition between the two growth rates for the N1 and N2 peak amplitudes. The specific parameter estimates of the final unconditional model are available from the first author by request.

Using these baseline developmental growth trajectories, the respective predictors of interest, WJ-R Word Attack group and WRAT$\mathrm{R}$ Reading group, were included in separate growth models as correlates of the maturational change in ERP waveforms. Separate models were run for each grouping (WJ-R Word Attack versus WRAT-R Reading) and for each peak amplitude and latency, yielding six growth trajectories of interest for each grouping. Because Espy et al. (2003) found specific growth differences between electrode sites and speech versus nonspeech stimuli conditions, follow-up analyses were run to determine whether there were specific relations between WJ$\mathrm{R}$ Word Attack grouping or WRAT-R Reading grouping, and electrode recording site by speech versus nonspeech stimuli condition. Although hemisphere differences can be noted in the ERP waveforms across ages (Figures 1 and 2), hemisphere was not included as predictor here since ERP differences between hemispheres did not appear to change across development in Espy et al. (2003). In order to minimize spurious findings, these follow-up analyses were conducted only on 


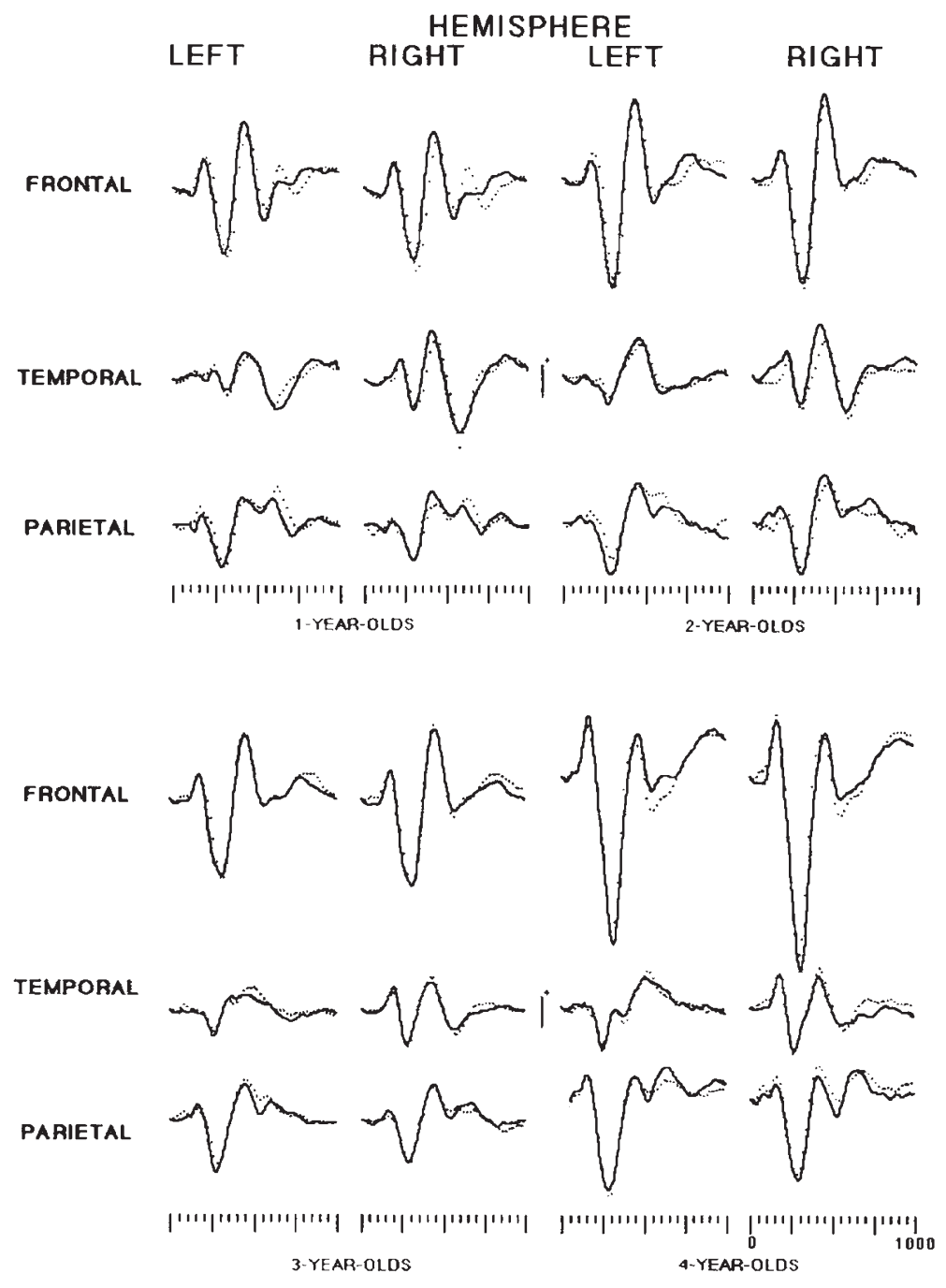

Figure 1. Group averaged auditory ERPs recorded from six scalp electrodes, over left and right frontal, temporal, and parietal regions of 1- through 4-year-old infants and children in response to speech (solid line) and nonspeech (dashed line) syllables. ERPs are averaged across consonant sounds. Waveform duration includes an initial $75 \mathrm{~ms}$ prestimulus baseline period followed by the $925 \mathrm{~ms}$ ERP. Time calibration markers occur at $50 \mathrm{~ms}$ intervals. Central calibration marker is $2.5 \mu \mathrm{V}$. 


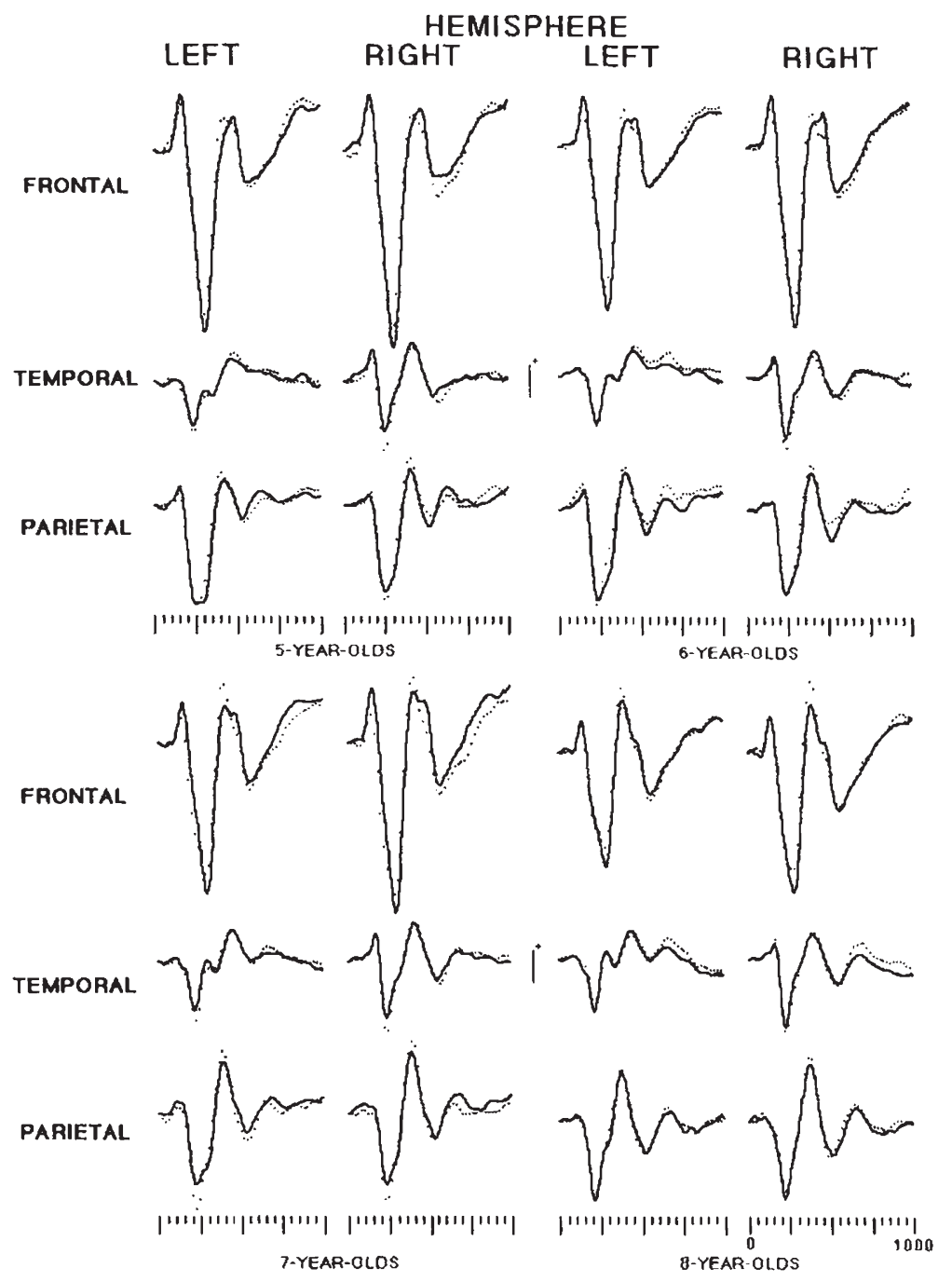

Figure 2. Group averaged auditory ERPs recorded from six scalp electrodes over left and right frontal, temporal, and parietal regions of children from 5 through 8 years of age in response to speech (solid line) and nonspeech (dashed line) syllables. ERPs are averaged across consonant sounds Waveform duration includes an initial 75 ms prestimulus baseline period followed by the 925 ms ERP. Time calibration markers occur at 50 ms intervals. Central calibration marker is $2.5 \mu \mathrm{V}$. 
the effects that were significant in the conditional models (e.g., if there were differences in the change in N1, but not N2, amplitude with age, specific analyses of the reading group differences at each recording site for speech and nonspeech stimuli conditions were conducted only for N1 amplitude).

\section{Results}

The group averaged ERPs for each age tested from ages 1 through 8 years that were elicited by the speech and nonspeech syllables are presented in Figures 1 and 2, respectively. The averaged ERPs are averaged across the different consonant sounds because the effects highlighted in this paper focus on the speech versus nonspeech conditions.

The relations of WJ-R Word Attack and WRAT-R Reading groups to the growth parameters that describe the ERP development between ages 1 through 8 years are contained in Tables I and II, respectively. For WJ-R Word Attack, some growth parameters describing development of the ERP N1 and N2 peaks differed as a function of group. For the following results, all $F$ values reflect those at the centered age of 4 years. For the ERP peak N1, the linear slope $(F[1,15634]=6.06, p$ $<.02)$, quadratic acceleration $(F[1,15634]=8.62, p<.003)$, and cubic $(F[1,15634]=9.13, p<.002)$ parameters representing change in amplitude only during the early observation period from ages 1 through 4 years differed between the Word Attack-average (WA-AVG) and Word Attack-low (WA-LOW) groups. Specifically relative to the WAAVG group, the linear rate of change in N1 amplitude at age 4 years for the WA-LOW group was more steeply negative (a rate difference of $-7.41 \mu \mathrm{V})$, as were the both the quadratic acceleration $(-8.80$ $\mu \mathrm{V})$ and cubic $(-2.171 \mu \mathrm{V})$ terms, averaged across electrode recording sites, stimuli condition, and hemisphere. There were no group-related differences in N1 amplitude growth in the later observation period, nor in the rates of maturation of P2 or N2 amplitudes. Furthermore, the growth trajectories in ERP latencies for the N1, P2, or N2 waveforms were comparable between the WA-AVG and WA-LOW.

As these noted differences were averaged across electrode recording site, hemisphere, and stimuli condition, follow-up analyses were conducted on the growth of N1 and N2 amplitudes to determine whether the specific developmental trajectories for each electrode recording site and speech versus nonspeech stimuli conditions were related specifi- 
Table I. Results of the Conditional Models - WJ-R Word Attack Groups.

\begin{tabular}{|c|c|c|c|c|}
\hline \multirow[b]{2}{*}{ Parameter } & \multicolumn{2}{|c|}{$\begin{array}{c}\text { Average }(\geq 90) \\
\text { WJ-R Word Attack } \\
\text { Group }(n=96)\end{array}$} & \multicolumn{2}{|c|}{$\begin{array}{c}\text { Low }(\leq 89) \\
\text { WJ-R Word Attack } \\
\text { Group }(n=13)\end{array}$} \\
\hline & M & SE & $\mathrm{M}$ & SE \\
\hline \multicolumn{5}{|l|}{ N1 - Amplitude } \\
\hline $\begin{array}{l}\text { Intercept } \\
\text { Slope }\end{array}$ & $-12.77^{* * * *}$ & 0.39 & $-12.73^{* * * *}$ & 1.17 \\
\hline Early* & $-11.52^{* * * *}$ & 1.00 & $-18.93^{\prime \prime * * *}$ & 3.01 \\
\hline Later & 0.15 & 0.31 & -0.12 & 0.92 \\
\hline \multicolumn{5}{|l|}{ Acceleration } \\
\hline Early** & $-7.07^{* * * *}$ & 1.01 & $-15.87^{\prime \prime * * *}$ & 3.00 \\
\hline Later & 0.10 & 0.07 & $0.23^{*}$ & 0.20 \\
\hline Cubic Early** & $-1.31 * * * *$ & 0.25 & $-3.48^{* * * *}$ & 0.72 \\
\hline \multicolumn{5}{|l|}{ N1 - Latency } \\
\hline Intercept & $222.75^{* * * *}$ & 1.83 & $224.64^{* * * *}$ & 4.77 \\
\hline Slope & $-10.98^{\prime \prime * * *}$ & 0.92 & $-10.20^{* * *}$ & 2.37 \\
\hline Acceleration & $-1.26^{* * * *}$ & 0.32 & -0.75 & 0.83 \\
\hline Cubic & $0.22^{*}$ & 0.10 & 0.22 & 0.27 \\
\hline \multicolumn{5}{|l|}{ P2 - Amplitude } \\
\hline Intercept & $7.38^{* * * *}$ & 0.19 & $7.61^{11 * * *}$ & 0.48 \\
\hline \multicolumn{5}{|l|}{ P2 - Latency } \\
\hline Intercept & $376.34^{* * * *}$ & 3.08 & $376.19^{* * *}$ & 7.83 \\
\hline Slope & $-6.75^{* * * *}$ & 0.83 & $-4.36^{* * *}$ & 2.10 \\
\hline Acceleration & $-2.19^{\prime \prime * * *}$ & 0.37 & $-1.75^{*}$ & 0.93 \\
\hline \multicolumn{5}{|l|}{ N2 - Amplitude } \\
\hline Intercept & $-6.20 * * * *$ & 0.25 & $-7.64^{* * * *}$ & 0.35 \\
\hline \multicolumn{5}{|l|}{ Slope } \\
\hline Early & $-5.06^{* * * *}$ & 0.71 & $-7.96^{* * * *}$ & 0.76 \\
\hline Later & 0.29 & 0.23 & $1.32^{* *}$ & 0.59 \\
\hline \multicolumn{5}{|l|}{ Acceleration } \\
\hline Early & $-3.01^{* * * *}$ & 0.69 & $-4.76^{* * * *}$ & 0.69 \\
\hline Later & -0.09 & 0.05 & -0.22 & 0.14 \\
\hline Cubic Early & $-0.48^{*}$ & 0.19 & -0.79 & 0.49 \\
\hline \multicolumn{5}{|l|}{ N2 - Latency } \\
\hline Intercept & $522.50 * * * *$ & 3.82 & $521.68^{* * * *}$ & 9.73 \\
\hline Slope & -2.11 & 1.31 & -2.72 & 3.21 \\
\hline Acceleration & $-2.64^{* * * *}$ & 0.54 & -1.16 & 1.37 \\
\hline
\end{tabular}

Early $=$ ages 1 through 4 years, Later $=$ ages 4 through 8 years. All expected values of growth parameters at centered age (4 years).

${ }^{*} p<.05 ;{ }^{* *} p<.01 ;{ }^{* * *} p<.001 ;{ }^{* * * *} p<.0001$ 
Table II. Results of the Conditional Models - WRAT-R Reading Groups.

\begin{tabular}{|c|c|c|c|c|}
\hline \multirow[b]{2}{*}{ Parameter } & \multicolumn{2}{|c|}{$\begin{array}{c}\text { Average }(\geq 90) \\
\text { WRAT-R Reading } \\
\text { Group }(n=79)\end{array}$} & \multicolumn{2}{|c|}{$\begin{array}{c}\text { Low }(\leq 89) \\
\text { WRAT-R Reading } \\
\text { Group }(n=30)\end{array}$} \\
\hline & M & SE & M & SE \\
\hline \multicolumn{5}{|c|}{ Peak 1 - Amplitude } \\
\hline Intercept & $-212.40^{* * * *}$ & 0.29 & $-213.29^{* * * *}$ & 0.54 \\
\hline \multicolumn{5}{|l|}{ Slope } \\
\hline Early & $-212.38^{* * * *}$ & 1.04 & $-211.78^{* * * *}$ & 2.00 \\
\hline Later & 0.04 & 0.17 & 0.19 & 0.33 \\
\hline \multicolumn{5}{|l|}{ Acceleration } \\
\hline Early & $-28.24^{* * * *}$ & 1.14 & $-27.54^{* * * *}$ & 2.35 \\
\hline Later & $0.12^{*}$ & 0.06 & $0.12^{*}$ & 0.06 \\
\hline Cubic Early & $-21.61 * * * *$ & 0.28 & $-21.44^{* * * *}$ & 0.58 \\
\hline \multicolumn{5}{|c|}{ Peak 1 - Latency } \\
\hline Intercept & $221.68^{* * * *}$ & 1.96 & $226.88^{* * * *}$ & 3.80 \\
\hline Slope & $-210.36^{* * * *}$ & 0.99 & $-212.28^{* * * *}$ & 1.91 \\
\hline Acceleration & $-21.05^{* * * *}$ & 0.34 & $-21.58^{* * * *}$ & 0.67 \\
\hline Cubic & 0.14 & 0.11 & 0.44 & 0.21 \\
\hline \multicolumn{5}{|c|}{ Peak 2 - Amplitude } \\
\hline Intercept & $7.23^{* * * *}$ & 0.20 & $7.92^{* * * *}$ & 0.39 \\
\hline \multicolumn{5}{|c|}{ Peak 2 - Latency } \\
\hline Intercept & $376.80^{* * * *}$ & 3.32 & $375.07^{* * * *}$ & 6.35 \\
\hline Slope & $-26.41^{* * * *}$ & 0.90 & $-26.28^{* * * *}$ & 1.72 \\
\hline Acceleration & $-22.40^{* * * *}$ & 0.40 & $-23.40^{* * *}$ & 0.75 \\
\hline \multicolumn{5}{|c|}{ Peak 3 - Amplitude } \\
\hline Intercept $t^{* *}$ & $-26.09 * * * *$ & 0.20 & $-27.21^{* * * *}$ & 0.39 \\
\hline \multicolumn{5}{|l|}{ Slope } \\
\hline Early & $-25.52^{* * * *}$ & 0.76 & $-25.82^{* * * *}$ & 1.56 \\
\hline Later** & 0.25 & 0.13 & $0.97^{* * *}$ & 0.26 \\
\hline \multicolumn{5}{|l|}{ Acceleration } \\
\hline Early & $-23.49^{* * * *}$ & 0.82 & $-23.21^{* * * *}$ & 1.72 \\
\hline Later* & $-20.08^{* *}$ & 0.03 & $-20.20 * * *$ & 0.06 \\
\hline Cubic Early & $-20.59 * * *$ & 0.20 & -20.50 & 0.40 \\
\hline \multicolumn{5}{|c|}{ Peak 3 - Latency } \\
\hline Intercept & $519.49^{* * * *}$ & 4.09 & $530.17^{* * * *}$ & 7.82 \\
\hline Slope & -21.62 & 1.41 & -23.88 & 2.70 \\
\hline Acceleration & $-22.39 * * * *$ & 0.59 & $-2.43^{* *}$ & 1.12 \\
\hline
\end{tabular}

Early = ages 1 through 4 years, Later = ages 4 through 8 years. All expected values of growth parameters at centered age (4 years).

${ }^{*} p<.05 ;{ }^{* *} p<.01 ;{ }^{* * *} p<.001 ;{ }^{* * *} p<.0001$ 

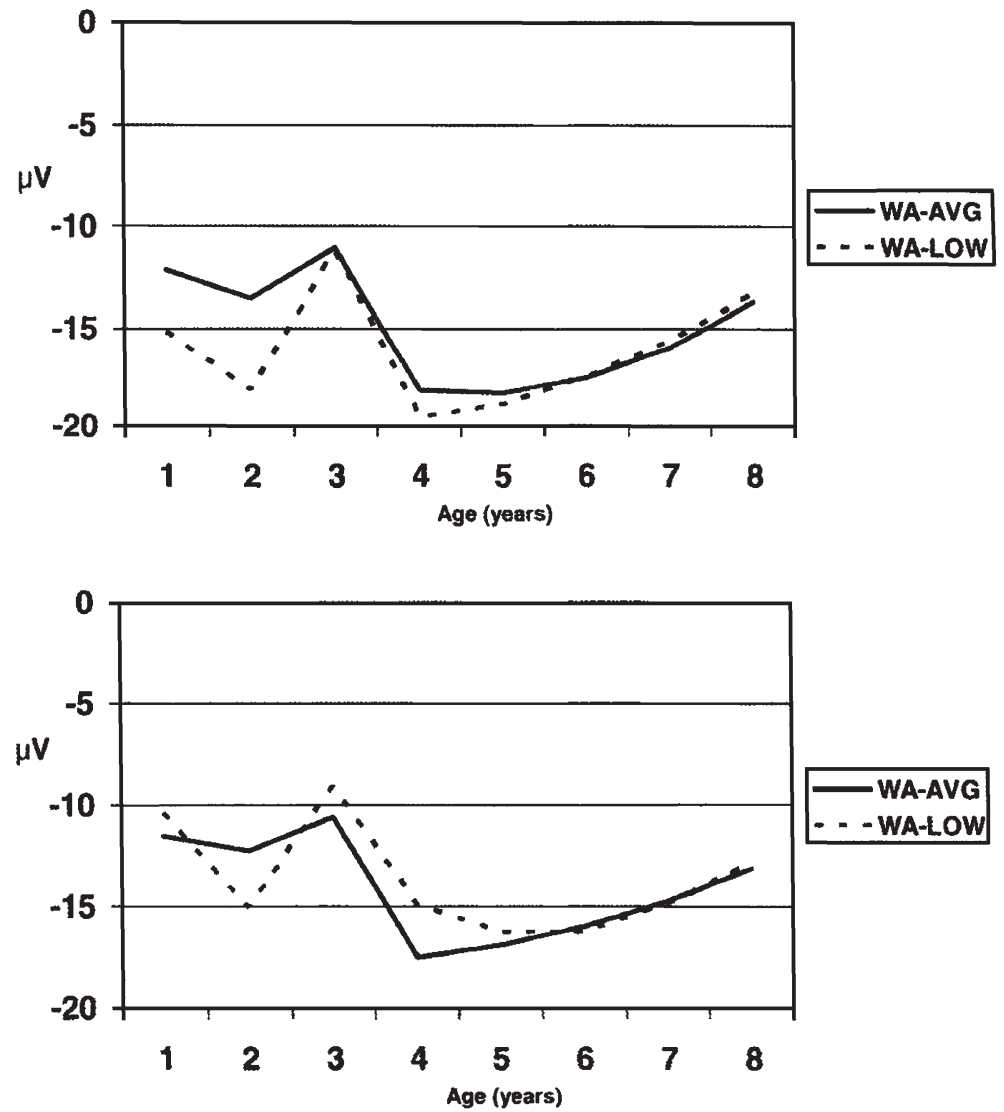

Figure 3. Top: N1 amplitude by WJ-R word attack groups for frontal recording site, speech stimuli condition. Bottom: N1 amplitude by WJ-R Word Attack groups for frontal recording site, nonspeech stimuli condition.

cally to WJ-R Word Attack groups. Analyses were conducted only on those variables that were significant in the averaged analyses in order to reduce the likelihood of spurious findings, given the number of comparisons that could be conducted six for each of three-peak amplitude and latency measures). The growth parameters that were related to WJ$\mathrm{R}$ Word Attack group are presented in Table II. Significant group differences are depicted graphically in Figures 3 through 6.

There were specific relations of the early change in N1 amplitudes in those ERPs recorded to speech sounds at the frontal, temporal, and parietal sites. For the frontal $(F[1,2174]=3.83, p<.05)$ and parietal $(F[1$, $2174]=6.34, p<.01$ ) recording sites, the linear change in N1 amplitudes to speech sounds at age 4 years were more steeply negative in the WA- 

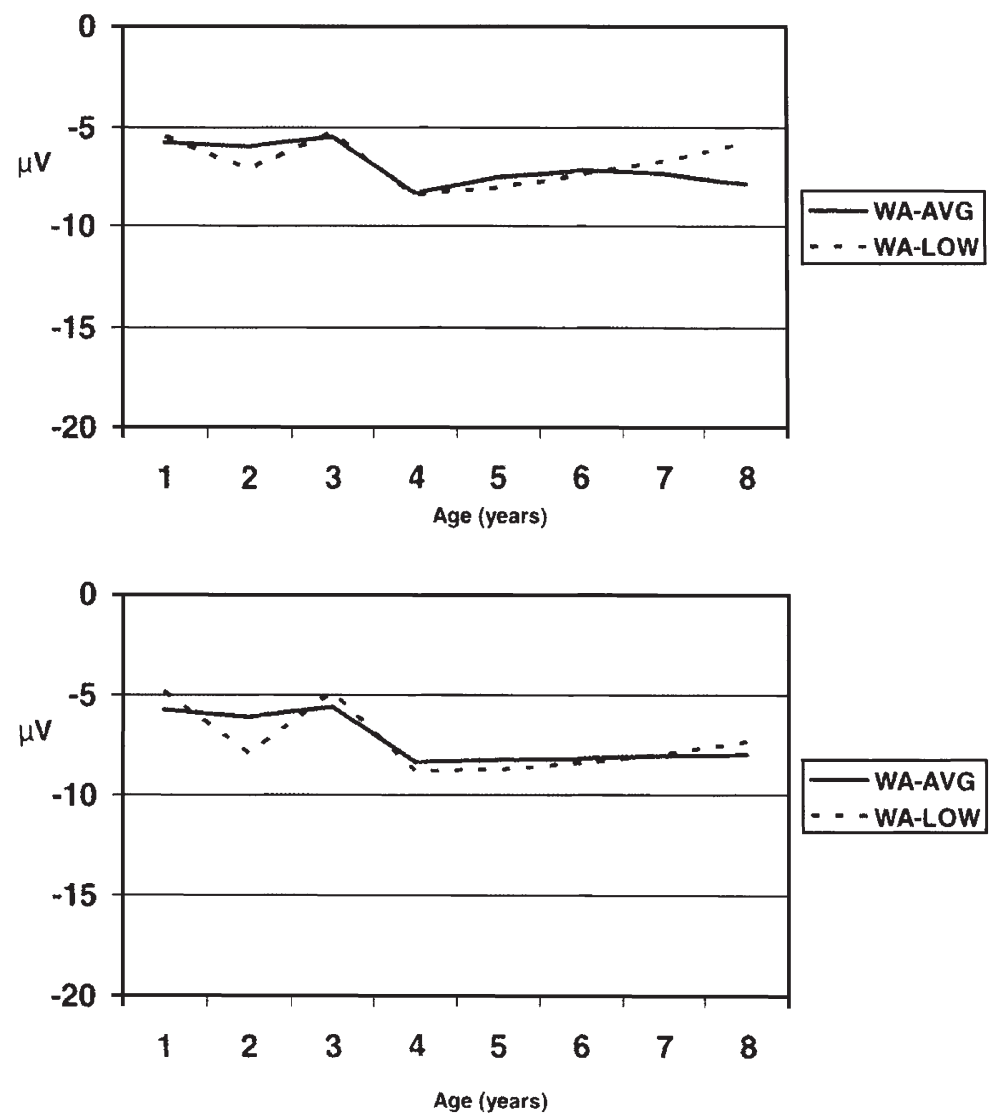

Figure 4. Top: N1 amplitude by WJ-R Word Attack groups for temporal recording site, speech stimuli condition. Bottom: N1 amplitude by, WJ-R Word Attack groups for temporal recording site, nonspeech stimuli condition.

LOW group relative to the WA-AVG group only in the age 1- to 4-year period. The difference in the linear slope at age 4 years at the frontal and parietal recording sites for speech sound stimuli for the WA-AVG and WA-LOW groups was -12.60 and $-10.47 \mu \mathrm{V}$, respectively. For the frontal recording site, differences in the trajectories of change in N1 amplitude between the WA-AVG and WA-LOW groups also were evident in the quadratic acceleration and cubic growth parameters, both in the speech and the nonspeech stimuli conditions. In response to speech stimuli, the acceleration $(F[1,2174]=5.72, p<.02)$ and cubic $(F[1,21741$ $=5.51, p<.02)$ terms were more steeply negative, with respective differences in amplitude of $-12.55 \mu \mathrm{V}$ and $-3.01 \mu \mathrm{V}$. A similar pattern of group differences were observed at the frontal recording site in re- 

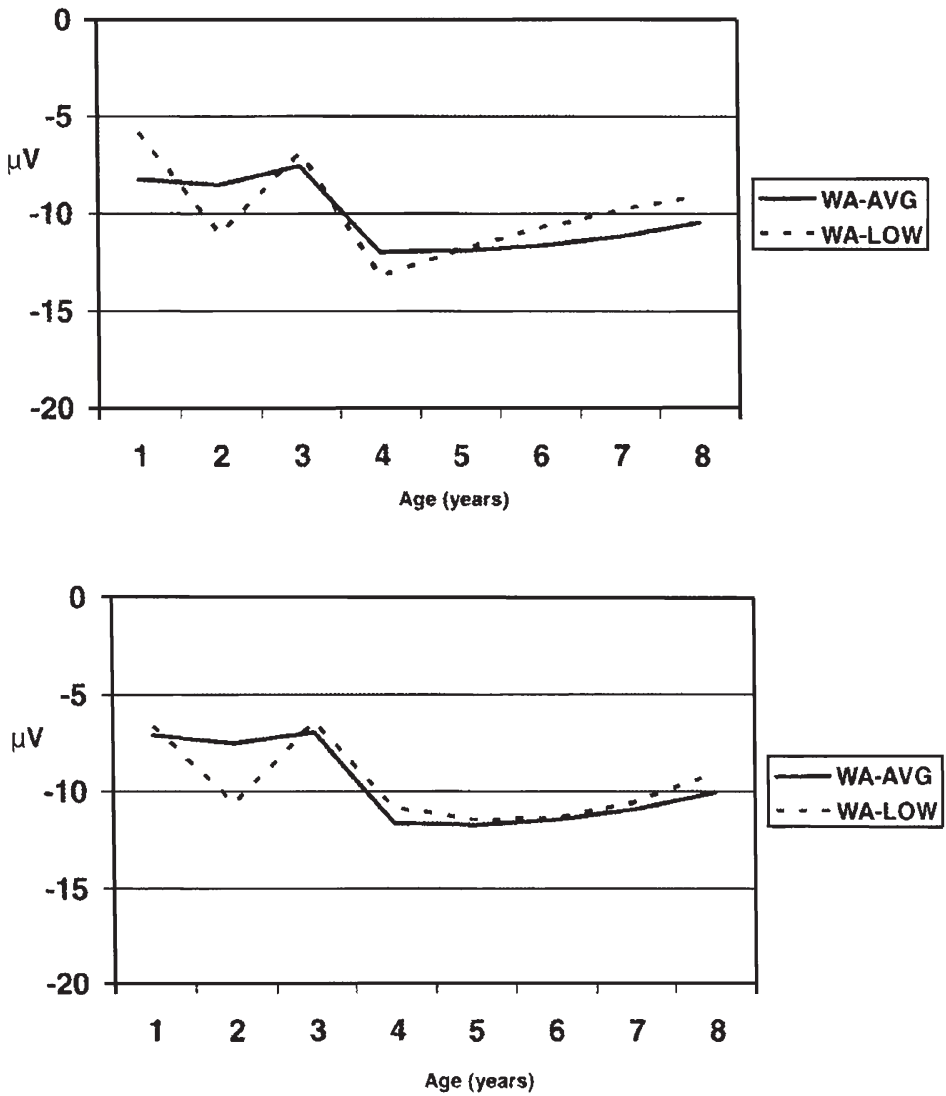

Figure 5. Top: N1 amplitude by WJ-R Word Attack groups for parietal recording site, speech stimuli condition. Bottom: N1 amplitude by WJ-R Word Attack groups for parietal recording site, nonspeech stimuli condition.

sponse to nonspeech sounds, again where the acceleration $(F[1,2174]$ $=3.90, p<.05)$ and cubic $(F[1,2174]=4.82, p<.03)$ terms were more steeply negative, by $-9.65 \mu \mathrm{V}$ and $-2.49 \mu \mathrm{V}$, respectively.

For the parietal recording site, the quadratic acceleration $(F[1$, $2174]=8.05, p<.005)$ and cubic change $(F[1,2174]=8.89, p<.003)$ in N1 amplitude during the early observation period also differed between the WA-AVG and WA-LOW groups, but only for the speech sound stimuli condition. Again, the magnitude of the effects for the quadratic and cubic change in N1 amplitude during the period from 1 through 4 years were more steeply negative with the group difference in quadratic acceleration and cubic growth parameters of $-10.47 \mu \mathrm{V}$ and $-2.85 \mu \mathrm{V}$, respectively. 

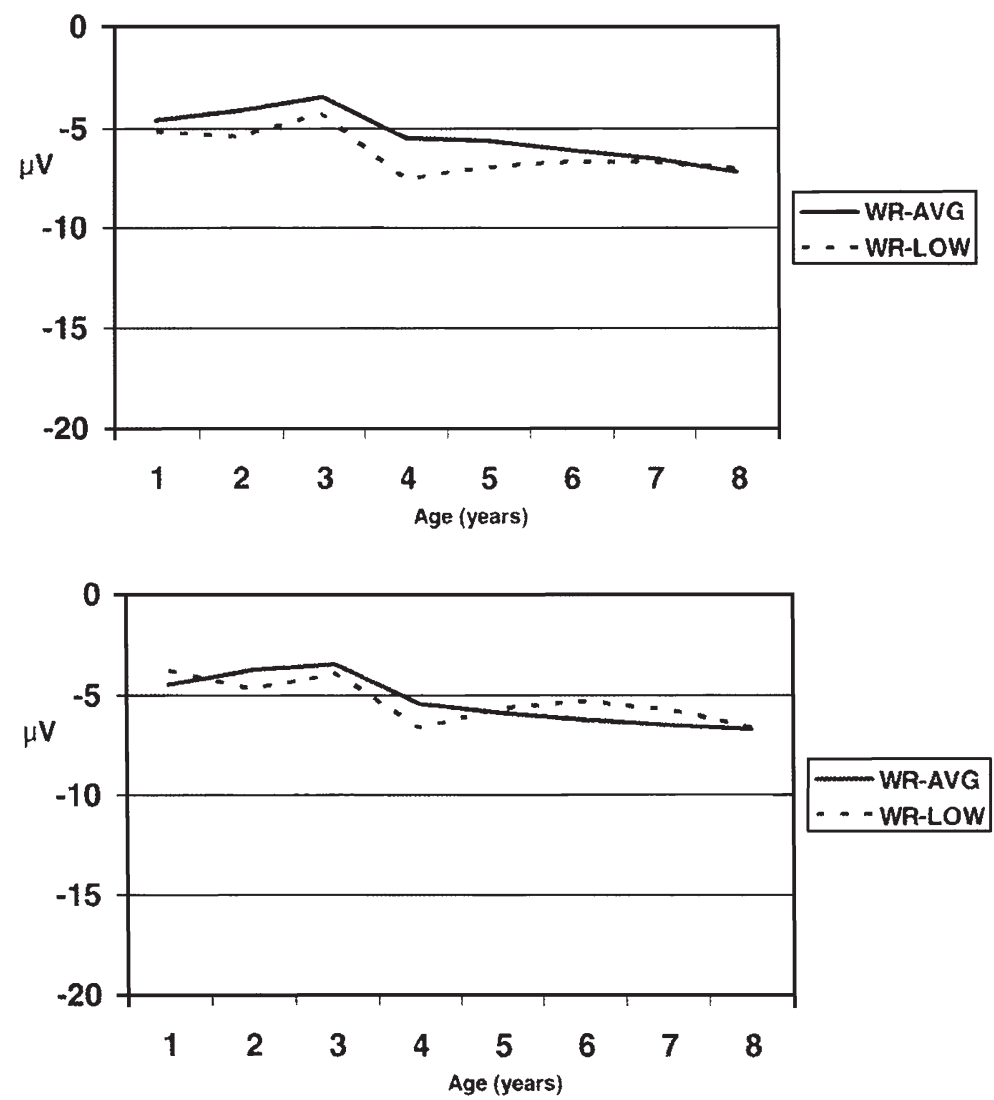

Figure 6. Top: N2 amplitude by WRAT-R Reading groups for parietal recording site, speech stimuli condition. Bottom: N2 amplitude by WRAT-R Reading groups for parietal recording site, nonspeech stimuli condition.

Interestingly, for the temporal recording sites, the WJ-R word attack groups differed in the development of the N1 amplitude, only in the nonspeech stimuli condition. The linear change in N1 amplitude in response to nonspeech sounds at the temporal recording sites for the WA-LOW group was more steeply negative $(-6.78 \mu \mathrm{V})$, than those for the WA-AVG group, $F(1,2174)=4.92, p<.03$, where this difference was apparent only for the early developmental period between ages 1 and 4 years. Furthermore, the quadratic acceleration, $F(1,2174)$ $=6.13, p<.02$, and cubic, $F(1,2174)=6.30, p<.02$, parameters for N1 amplitude growth were more negative for the WA-LOW group, relative to the WA-AVG group, again only for the early period by -7.53 $\mu \mathrm{V}$ and $1.82 \mu \mathrm{V}$, respectively. 
Figures 3, 4, and 5 depict the growth curves for the N1 waveform for the frontal, temporal and parietal recording sites, respectively. In Figure 3, differences in the growth parameters as a function of WJ-R Word Attack groups are evident. The N1 amplitude recorded at the frontal leads in response to speech stimuli were more negative during the early observation period with steeper changes in amplitude, particularly between ages 2 and 3, and 3 and 4 years. Such a consistent pattern between groups also is evident for the nonspeech stimuli depicted in the bottom half of figure 3, although the group differences in the magnitude of the developmental changes are attenuated. A pattern similar to that observed at the frontal recording sites is evident in figure 5 for the parietal sites, where there are pronounced differences in N1 amplitudes recorded in response to speech sounds between the WA-AVG and WA-LOW groups in the early observation period, with steeper changes in ERP growth in the WA-LOW group for the speech condition and more attenuated changes for the nonspeech condition.

In contrast, for the temporal recording sites depicted in Figure 4, the difference in the developmental trajectories between the WAAVG and WA-LOW group was evident only for the nonspeech stimuli conditions. In response to speech stimuli, the growth trajectories of N1 amplitudes are similar between the WA-AVG and WA-LOW groups. For nonspeech sounds, change in N1 amplitudes for children in the WA-LOW group was steeper during the early observation period than for children in the WA-AVG group.

For WRAT-R reading groups, the group-related differences in the trajectories of ERP development differed substantially relative to results for the groups formed using WJ-R Word Attack. In Table II, growth parameters describing development of the N2 peak amplitude as a function of group are shown. For peak N2, the expected amplitude at age 4 years, linear slope, quadratic acceleration in amplitude during the later observation period from ages 4 through 8 years only differed between the WRAT-R average (WR-AVG) and WRATR low (WR-LOW) groups. Specifically relative to the WR-AVG group, the expected amplitude at age 4 years was more negative for the WRLOW group by $-1.12 \mu \mathrm{V}, F(1,15634)=7.93, p<.005$. The linear rate of change in $\mathrm{N} 2$ amplitude at age 4 years for the WR-LOW group was more steeply positive, $F(1,15634)=7.71, p<.006$, relative to that of the WR-LOW group. Interestingly, the difference in the quadratic acceleration of N2 amplitude growth also was steeper in the WR-LOW group in comparison to that of the WR-AVG; however, here, acceleration was more negative; that is, a greater attenuation in the more 
positive slope with advancing age, $F(1,15634)=3.87, p<.05$. These group-related differences in $\mathrm{N} 2$ growth were evident only for the later observation period; that is, from age 4 through 8 years. There were no group-related differences in N2 amplitude growth in the early observation period, nor in the maturation of N1 or P2 amplitudes. Finally, WRAT-R reading groups were comparable in the trajectories of ERP growth for the N1, P2, and N2 latencies.

Table III contains the group-related differences in N2 amplitude growth, broken down by electrode recording site and stimuli condition. Group related differences were apparent only in the nonspeech stimulus condition at the parietal recording site. The linear slope of N2 amplitude growth during the later observation period for the WR-LOW group was $1.81 \mu \mathrm{V}$ more than the WR-AVG group at age 4 years, $F(1,2174)=5.05, p<.03$. Acceleration also was more steeply negative in the WR-AVG group during the same period, $F(1,2174)-$ $3.81, p<.05$ relative to the WR-AVG group for the nonspeech stimuli condition at the parietal recording site only. There were no group-related differences in ERP growth (slope, acceleration, or cubic parame-

Table III. Significant Group Differences in ERP Peak Amplitudes by Recording Site and Stimuli Conditions $(n=109)$ at centered age (4 years).

\begin{tabular}{|c|c|c|c|}
\hline Predictor & Frontal & Temporal & Parietal \\
\hline & \multicolumn{3}{|c|}{ WJ-R Word Attack Grouping } \\
\hline \multirow{4}{*}{$\begin{array}{l}\text { N1 Amplitude } \\
\text { Speech }\end{array}$} & & & \\
\hline & $\mathrm{ES},-12.60^{*}$ & None & $\mathrm{ES},-10.47^{*}$ \\
\hline & $\mathrm{EA},-12.55^{*}$ & & $\mathrm{EA},-11.55^{* *}$ \\
\hline & $\mathrm{EC},-3.01^{*}$ & & $\mathrm{EC},-2.85^{\star *}$ \\
\hline \multirow[t]{3}{*}{ Nonspeech } & & $\mathrm{ES},-6.78^{*}$ & \\
\hline & EA, $-9.65^{*}$ & & $\mathrm{EA},-7.53^{*}$ \\
\hline & EC, $-2.49^{*}$ & & $\mathrm{EC},-1.82^{*}$ \\
\hline & \multicolumn{3}{|c|}{ WRAT-R Reading Grouping } \\
\hline \multirow{4}{*}{$\begin{array}{l}\text { N2 Amplitude } \\
\text { Speech } \\
\text { Nonspeech }\end{array}$} & & & \\
\hline & None & None & $\mathrm{I},-2.12^{* *}$ \\
\hline & None & None & LS, $1.81^{*}$ \\
\hline & & & LA, $-0.38^{*}$ \\
\hline
\end{tabular}

All expected values of growth parameters at centered age (4 years). ES = Early Slope, ages 1 through 4 years, EA = Early Acceleration, ages 1 through 4 years, $\mathrm{EC}=$ Early Cubic, ages 1 through 4 years, I = Intercept; LS = Later Slope, ages 4 through 8 years; LA = Later Acceleration, ages 4 through 8 years.

${ }^{*} p<.05 ;{ }^{* *} p<.01$. Correlates of ERP Growth 
ters) at the frontal or temporal recording sites, regardless of the stimuli condition, nor at the parietal site for the speech conditions. There was a difference in expected amplitude at age 4 years between the WR-LOW and WR-AVG groups of $-2.12 \mu \mathrm{V}, F(1,2174)=7.11, p<.008$ for the speech condition at the parietal site only.

The group-related differences in the trajectory of development of the N2 amplitude at the parietal recording site for the WRAT-R reading groups are depicted in figure 6. In the nonspeech condition (bottom of Figure 6), the more positive rate of change in amplitude in the later observation period from ages 4 through 8 years is apparent where the difference between the WR-LOW and WR-AVG groups attenuates over time. For the speech condition, there is a consistent difference in N2 amplitude that is apparent across nearly all ages, with no significant differences in the shape of the trajectory, indicating linear slopes, acceleration and cubic parameters of similar magnitude.

\section{Discussion}

The purpose of the study was to examine changes in the development of ERP waveforms, specifically changes in the peak amplitudes and latencies of ERP waveforms to speech and nonspeech stimuli for a systematic relation to differences in reading proficiency at age 8 years. The development of ERP waveforms were posited to be more consistently related to reading proficiency assessed by the WJ-R Word Attack subtest than by the WRAT-R Reading subtest due to stronger reliance on phonological skills to decode pseudowords on the WJ-R Word Attack that are not confounded by familiarity as in the WRATR Reading subtest.

As predicted, and similar to earlier work reported by Molfese and Molfese, the relations between ERP responses to speech stimuli and reading scores was most evident for the early processing component, the N1 ERP waveform. The N1 waveform that was related to nonsense single pseudoword reading here is consistent with previously observed relations between the N1 waveform from newborn ERPs and language abilities at age 3 and 5 years (Molfese \& Molfese, 2000), and the identification of reading in disabled readers at age 8 (Molfese, 2000; Molfese, Molfese, \& Modglin, 2001). The present findings suggest that it is not just biologically based differences in the processing auditory information in the newborn brain that underlie later cognitive proficiencies. In addition, it is the early development (between 
the ages of 1 and 4 years) of these brain-based perceptual skills, manifested by changes in ERP N1 amplitudes, that provides a dynamic platform for the later development of language related abilities such as reading skills.

The change in amplitude in the N1 waveform from ages 1 through 4 differed between average and poorer readers defined by the WJ-R Word Attack subtest. In this early developmental period, the changes in N1 amplitude also were most dramatic, relative to age 4 years and beyond. Given the basic and fundamental nature of perception, it is not surprising that only early changes in perceptual abilities are related to subsequent nonsense pseudoword reading proficiency. The observed differences in the development of these basic neurally based perceptual abilities may underlie the faulty processing of speech-related information postulated by other researchers as underlying the development of reading skills (Kraus, et al., 1996; Merzenich, et al., 1996; Tallal, et al., 1996; Leppänen, et al., 2002).

The nature of these individual differences in the N1 ERP waveform is important. The present study clearly indicates that variations in the development of $\mathrm{N} 1$ amplitudes after birth are related to subsequent reading proficiency. In less proficient readers, the N1 amplitudes were consistently more negative with a more rapid rate of change in the early observation period. Because ERPs likely reflect the maturation of neuronal activation patterns in the auditory cortex, both in neuronal circuitry (i.e., anatomy) as well as neuronal signaling (i.e., function) (Nunez, 1981; Molfese, Molfese, \& Kelly, 2001), these amplitude differences suggest that less proficient readers recruit greater cortical surface or volume than average readers to perceive auditory information that is critical for reading. Support for this hypothesis is provided by recent findings using high density array ERP techniques in which greater amplitude responses distributed over broader brain regions is observed in dyslexic/poor readers compared to average readers (Molfese, et al., 2003).

Unlike Molfese, Molfese, and Modglin (2001) who related newborn N1 amplitudes and latencies to the decoding of regular and irregular words in disabled readers, only differences in rates of maturation change in $\mathrm{N} 1$ amplitude were related specifically to nonsense pseudoword reading proficiency at age 8 years in the present study. Taken in combination with the preliminary evidence of the relation between N1 latency changes and verbal intelligence at age 8 years (Molfese, Molfese, \& Espy, 1999), the amplitude differences may reflect more specific relations between brain efficiencies in auditory per- 
ceptual processing, whereas latency changes may be more associated with general intellectual differences. Leppänen and Lyytinen (1997) have suggested that N1 amplitude differences between average and poor readers reflect both attention and "tuning" of the auditory system, where ERP latency differences may be related to a common timing deficit. Alternatively, variation in ERP latencies in the newborn period (Molfese, 2000) may be related to later language proficiencies, which could be investigated systematically in the future with a larger and more diverse sample of children with lower intelligence and/or language scores.

Our hypothesis that the early developmental trajectories of ERPs recorded in response to speech sounds are related more strongly to later reading proficiency was supported partially, at the frontal and parietal recording sites. Differences in the early development of ERPs to nonspeech stimuli also were related to subsequent nonsense pseudoword reading abilities at the temporal and frontal recording sites. These findings suggest that perceptual mechanisms to the full sound spectrum, both speech and nonspeech sounds, are important in later reading ability. Kuhl, Andruski, Christovich, and Christovich (1997) have shown that sensitivity to native and non-native language contrasts change during infancy, as the infant gradually loses sensitivity to the non-native language sounds as enculturation in the native language context and environment progresses. Infants whose language context differs, for example, within a bilingual environment, have a different pattern of change in sensitivity.

For reading, individual differences in the development of general perceptual abilities, which include neural responsivity to both speech and nonspeech sounds, are related to later nonsense word reading. Although there were reading group-related differences for speech and nonspeech stimuli by recording site, the localization of the source of the ERP within the brain is not isomorphic with the recording location due to the signal propagation patterns across brain tissue of different densities and skull. Therefore, scalp ERP recordings and voltage shifts across the scalp are not necessarily immediately adjacent to the underlying neural mechanisms that generate these voltages. In order to determine the spatial distribution within the brain of such neural generators of the specific ERP signals, source analyses (e.g., BESA) (Scherg \& Berg, 1996) need to be used that require recordings from a much larger number of electrodes in a high density array.

Finally, group-related differences in ERP development were more consistent when groups were selected according to WJ-R Word At- 
tack subtest performance than when WRAT-R Reading scores were used. Although N1 waveforms collected at birth have been related to WRAT-R performance in Molfese, Molfese, and Modglin (2001), in that study, the focus was on group differences in reading abilities. When the WRAT-R was used to select reading groups in the present study, ERP waveform differences also were evident; however, it was in the amplitudes of the second negative peak, N2, and only at later observation period from ages 4 through 8 years. Group differences were restricted further to the parietal recording site and differences in the change in amplitude were evident only for the nonspeech condition. These group related differences were not nearly as robust as those when reading groups were defined using the WJ-R Word Attack subtest, presumably related to the different, nonphonologically based cognitive processes that can be employed on the WRAT-R when some of the words are familiar. Behaviorally, pseudoword reading is considered to more strongly engage phonological processing abilities. The findings confirm this supposition by demonstrating greater specificity in the relation of developing brain-based measures of auditory perception and pseudoword reading.

These findings must be considered in the context of study limitations. Although a large sample of children were studied, relatively few of this general population of children obtained scores of $<90$ on the WJ-R Word Attack subtest. Although the growth parameter estimates for these children are likely quite stable, as children were followed longitudinally for such a long period of time and were assessed an average of six times during the observation period, sample variation may have contributed to these results. Because relatively fewer children scored at these low levels, reading groups were formed on the basis of performance cut-offs that are higher than those that might be used with a population with more variability in performance scores to examine differences in brain-based perceptual skills, as manifested by ERP development and later reading proficiency. A larger sample that included more children with very poor WJ-R Word Attack scores would be useful to further test the nature of the observed relations. Because ERPs discriminated between readers across such a narrow range of reading levels, discriminabilty might be further enhanced if children with a broader range of skills were tested. Nonetheless, one important aspect of the present design is the use of hierarchical linear models that specify the developmental processes of ERP change to speech and nonspeech sounds in children from ages 1 through 8 years. These models offer a powerful approach to better understand 
the true developmental trajectories of basic perceptual skills and cognitive abilities, and highlight the individual variation among children that may be an important determinant of later academic success.

\section{Acknowledgments}

This research was supported, in part, by grants from the Blowitz-Ridgeway Foundation, the National Science Foundation (BNS 8004429, BNS 8210846), the National Institutes of Health (R01-HD17860), and the U.S. Department of Education (R215K000023). The authors thank the dedicated families for their continued participation in this longitudinal study.

\section{References}

Brady, S. (1991). The role of working memory in reading disability. In S. Brady \& D. Shankweiler (Eds.), Phonological Processes in Literacy: A Tribute to Isabelle Y. Liberman (pp. 129-161). Hillsdale, NJ: Erlbaum.

Cutting, J. (1974). Two left-hemisphere mechanisms in speech perception. Perception $\mathcal{E}$ Psychophysics, 16, 601-612.

Denton, K., \& West, J. (2002). Children's Reading and Mathematics Achievement in Kindergarten and First Grade. Washington, DC: U.S. Department of Education, National Center for Education Statistics.

Eilers, R. (1977). Context-sensitive perception of naturally produced stop and fricative consonants by infants. Journal of the Acoustical Society of America, 61, 1321-1336.

Eilers, R., Wilson, W., \& Moore, J. (1977). Developmental changes in speech discrimination in infants. Journal of Speech and Hearing Research, 20, 766-780.

Eimas, P., Siqueland, E., Jusczyk, P., \& Vigorito, J. (1971). Speech perception in infants. Science, 171, 303-306.

Espy, K. A., Francis, D. J., \& Riese, M. L. (2000). Prenatal cocaine exposure and prematurity: Developmental growth. Developmental and Behavioral Pediatrics, 21,264-272.

Espy, K. A., Molfese, D. L., Simos, P., \& Modglin, A. (2003). Individual differences in the development of auditory event-related potentials. Manuscript submitted for publication.

Espy, K. A., Riese, M. L., \& Francis, D. J. (1997). Neurobehavior in preterm neonates exposed to cocaine, alcohol, and tobacco. Infant Behavior and Development, 20, 297-309.

Fletcher, J., Foonnan, B., Shaywitz, S., \& Shaywitz, B. (1999). Conceptual and methodological issues in dyslexia research: A lesson for developmental disorders. In $\mathrm{H}$. Tager-Flusberg (Ed.), Neurodevelopmental Disorders (pp. 271-305). Cambridge, MA: MIT Press.

Francis, D. J., Fletcher, J. M., Steubing, K. K., Davidson, K. C., \& Thompson, N. M. (1991). Analysis of change: Modeling individual growth. Journal of Consulting and Clinical Psychology, 59, 27-37.

Francis, D., Shaywitz, S., Stuebing, K., Shaywitz, B., \& Fletcher, J. (1996). Developmental lag versus deficit models of reading disability: A longitudinal, individual growth curves analysis. Journal of Educational Psychology, 88, 3-17.

Jasper, H. H. (1958). The ten-twenty electrode system of the International Federation of Societies for Electroencephalography. Appendix to the report of the committee 
of methods of clinical examination in electroencephalography. Journal of Electroencephalography and Clinical Neurophysiology, 10, 371-375.

Jastak, S., \& Wilkinson, G. (1984). The Wide Range Achievement Test-Revised. Wilmington, DE: Jastak.

Huttenlocher, J., Haight, W., Bryk, A., Seltzer, M., \& Lyons, T. (1991). Early vocabulary growth: Relation to language input and gender. Developmental Psychology, 27, 236-248.

Kraus, N., McGee, T., Carrell, T., Zecker, S., Nicol, T., \& Koch, D. (1996). Auditory neurophysiologic responses and discrimination deficits in children with learning problems. Science, 273,971-973.

Kuhl, P., Andruski, J., Christovich, I., \& Christovich, L. (1997). Cross-language analysis of phonetic units in language addressed to infants. Science, 277, 684-686.

Leppänen, P., \& Lyytinen, H. (1997). Auditory event-related potentials in the study of developmental language disorders. Audiology and Neuro-Otology, 2, 308-340.

Leppänen, P., Richardson, U., Pihko, E., Eklund, K., Guttorm, T., Aro, M., \& Lyytinen, H. (2002). Brain responses to changes in speech sound durations differ between infants with and without familial risk for dyslexia. Developmental Neuropsychology, $22,407-422$.

Liberman, A., Cooper, F., Shankweiler, D., \& Studdert-Kennedy, M. (1967). Perception of the speech code. Psychological Review, 74, 431-461.

Little, R., \& Rubin, D. (1987). Statistical Analysis with Missing Data. New York: Wiley.

Merzenich, M., Jenkins, W., Johnston, P., Schreiner, C., Miller, S., \& Tallal, P. (1996). Temporal processing deficits of language-learning impaired children ameliorated by training. Science, 271, 77-81.

Molfese, D. L. (1988). Evoked Potential Analysis and Collection System (EPACS). USA.

Molfese, D. L. (2000). Predicting dyslexia at 8 years of age using neonatal brain responses. Brain and Language, 72, 238-245.

Molfese, D. L., Fonaryova Key, A., Molfese, V., Kelly, S., Cunningham, N., Rumage, C., Terrell, S., \& Ferguson, M. (2003). Brain response differences between dyslexic, average, and advanced readers. Paper presented at the 31st Annual Meeting of the International Neuropsychological Society, Honolulu Hawaii.

Molfese, D., \& Molfese, V. (1979a). Hemisphere and stimulus differences as reflected in the cortical responses to newborn infants to speech stimuli. Developmental Psychology, 15, 505-511.

Molfese, D., \& Molfese, V. (1979b). Infant speech perception: Learned or innate? In H. Whitaker \& H. Whitaker (Eds.), Advances in Neurolinguistics, (vol. 4.) (pp. 229-240). New York: Academic Press.

Molfese, D., \& Molfese, V. (1980). Cortical responses of preterm infants to phonetic and nonphonetic speech stimuli. Developmental Psychology, 16, 574-581.

Molfese, D., \& Molfese, V. (1985). Electrophysiological indices of auditory discrimination in newborn infants: The bases for predicting later language development. Infant Behavior and Development, 8, 197-211.

Molfese, D., \& Molfese, V. (1988). Right hemisphere responses from preschool children to temporal cues contained in speech and non-speech materials: Electrophysiological correlates. Brain and Language, 33, 135-156.

Molfese, D., \& Molfese, V. (1997). Discrimination of language skills at five years of age using event related potentials recorded at birth. Developmental Neuropsychology, 13, 133-156.

Molfese, D., \& Molfese, V. (2000). The continuum of language development during infancy and childhood: Electrophysiological correlates. In C. Rovee-Collier, L. Lip- 
sitt, \& R. Reese (Eds.), Progress in Infancy Research (vol. 1) (pp. 251-287). Mahwah, NJ: Erlbaum.

Molfese, D. L., Molfese, V. J., \& Espy, K. A. (1999). The predictive use of event related potentials in language development and the treatment of language disorders. Developmental Neuropsychology, 16, 373-377.

Molfese, D., Molfese, V., \& Kelly, S. (2001). The use of brain electrophysiology techniques to study language: A basic guide for the beginning consumer of electrophysiology information. Learning Disability Quarterly, 24, 177-188.

Molfese, D., Molfese, V., Key, S., Modglin, A., Kelley, S., \& Terrell, S. (2002). Reading and cognitive abilities: Longitudinal studies of brain and behavior changes in young children. Annals of Dyslexia, 52, 99-119.

Molfese, V., \& Molfese, D. (2002). Environmental and social influences as indexed by brain and behavioral responses. Annals of Dyslexia, 52, 121-137.

Molfese, V., Molfese, D., \& Modglin, A. (2001). Newborn and preschool predictors of second-grade reading scores: An evaluation of categorical and continuous scores. Journal of Learning Disabilities, 34, 545-554.

Nunez, P. (1981). Electric Fields in the Brain: The Neurophysics of EEG. New York: Oxford University Press.

Oldfield, R. (1971). The assessment and analysis of handedness: The Edinburgh inventory. Neuropsychologia, 9, 97-111.

Raudenbush, S. W., \& Bryk, A. S. (2002). Hierarchical Linear Models, 2nd Ed. Thousand Oaks, CA: Sage Publications.

Schafer, J. (1997). Analysis of Incomplete Multivariate Data. New York: Wiley.

Scherg, M., \& Berg, P. (1996). Brain Electromagnetic Source Analysis (BESA) User Manual. Munich, Germany: MEGIS.

Share, D. (1995). Phonological recoding and self-teaching: Sine qua non of reading acquisition. Cognition, 55, 151-218.

Tallal, P., Miller, S., Bedi, G., Byma, G., Wang, X., Nagarajan, S., Schreiner, C., Jenkins, W., \& Merzenich, M. (1996). Language comprehension in language-learning impaired children improved with acoustically modified speech. Science, 271, 81-84.

Vellutino, F., \& Scanlon, D. (1987). Phonological coding, phonological awareness, and reading ability: Evidence from a longitudinal and experimental study. MerrillPalmer Quarterly, 33, 321-363.

Wagner, R., Torgesen, J., \& Rashotte, C. (1994). Development of reading-related phonological processing abilities: New evidence of bidirectional causality from a latent variable longitudinal study. Developmental Psychology, 69, 848-872.

Wechsler, D. (1991). Wechsler Intelligence Scale for Children (3rd ed.). San Antonio, TX. The Psychological Corporation.

Willett, J. (1988). Questions and answers in the measurement of change. Reviews of Research in Education, 15, 345-422.

Woodcock, R. W., \& Johnson, M. B. (1989). Woodcock-Johnson Psycho-Educational Battery - Revised. Allen, TX: DLM Teaching Resources.

Yeates, K., Taylor, H. G., Drotar, D., Wade, S., Klein, S., Stancin, T., \& Schatschneider, C. (1997). Preinjury family environment as a determinant of recovery from traumatic brain injuries in school-age children. Journal of the International Neuropsychological Society, 3, 617-630. 